\title{
High Temperature Behavior of Superalloy under Simulating Gas Turbine Environment
}

\author{
ChellaGanesh.D, Adamkhan.M, WinowlinJappes JT
}

\begin{abstract}
On prolonged exposure of superalloys at elevated temperature, the surface degradation is prone to involve. In this study two nickel - based superalloys, Inconel617 and Hastelloy are the materials used to perform surface studies. The behaviors of superalloys at elevated temperatures are studied with and without salt mixture. Samples are exposed at $900^{\circ}$ and $1000^{\circ} \mathrm{C}$ for a period of fifty hours. From the investigation, the cumulative mass changes per unit area are calculated with reference to the proportion of surface scale formation. The substantial role of the alloying elements is analyzed through SEM and XRD analysis. The Hastelloy has better resistance towards corrosion and oxidation resistance than Inconel617. The predominant oxides formed during the exposure at high temperature have a major contribution towards the protection of the samples.
\end{abstract}

Keywords: Superalloys, oxidation, corrosion, molten salt, SEM.

\section{INTRODUCTION}

The turbine component which operates at elevated temperatures between $640^{\circ} \mathrm{C}$ to $1150^{\circ} \mathrm{C}$ is facing metallurgical changes on prolonged exposure. Due to presence of flue gas and salt deposits, the materials are vulnerable and lead to possible failure. To avoid this high temperature failure, suitable alloys are selected for turbine components. Nickel based superalloys are capable to withstand the high temperature. Superalloys exhibits good mechanical strength, surface stability, creep and fatigue resistance at turbine operating condition [1]. Mostly suitable for turbine, nuclear reactor and high temperature gas reactors due to their high mechanical properties. Superalloys find their largest application in the hot section of engine components and corrosive environments [2-5].At the time of working, the nickel - based alloys are susceptible towards chemical and electrochemical. Thus, corrosion attack turns to reduce the life span of the turbine components. The constitution of the combustion gas includes sulphur, sodium, vanadium, potassium, and lead from the fuel along with various halides from offshore atmosphere. During operation ingested into engine along hot hair, sulphur and sodium chlorides reacts to form molten salt of sodium sulfate and it reduce life of the component. [6-11]

Revised Manuscript Received on December 5, 2019

* Correspondence Author

First Author Name*, Department of Mechanical Engineering department, Kalasalingam Academy of Research \& Education, Virudhunagar Dist., Tamilnadu, India.Email: d.chellaganesh@klu.ac.in

Second Author Name, Department of Mechanical Engineering department, Kalasalingam Academy of Research \& Education, Virudhunagar Dist., Tamilnadu, India. Email: adamkhan.m@klu.ac.in

Third Author Name, Department of Mechanical Engineering department, Kalasalingam Academy of Research \& Education, Virudhunagar Dist., Tamilnadu, India Email: winowlin@klu.ac.in.
The materials are the alternate which are used in jet engines tail pipes, burner components and other aircrafts parts. [11]. Hastelloy material has combination of chemical substance of chromium and molybdenum which leads to resist from the hot corrosion [12]. For challenging environment Hastelloy material can be used as an alternate material operating at high temperature operating condition.

In this paper the hot corrosion behavior of Inconel617 and Hastelloy were investigated at two different temperatures, with salt and without salt. The obtained results are evaluated to compare the performance of the material. The metallurgical studies of exposed samples are studied with the help of SEM, EDS and XRD for better understanding of material property change

\section{MATERIAL AND METHODS}

In this study Inconel617 and Hastelloy are the candidate material. The samples are sliced with the help of electrical discharge machining process to a dimension of $10 \times 10 \times 3$ mm. Further samples polished through conventional metallographic methods using emery sheets and alumina powder. After polishing samples are cleaned with ethanol and initial weight of the samples are measured. Alumina boat are used to place the samples inside the furnace, at the two different temperatures at of $900^{\circ}$ and $1000^{\circ} \mathrm{C}$.Mixed salt with a proportion of $75 \% \mathrm{Na}_{2} \mathrm{SO}_{4}$ and $25 \% \mathrm{NaCl}$ (wt. \%) are used to apply over the surface at a rate on $3.5-5 \mathrm{~g} / \mathrm{cm}^{2}$. The investigations are made for fifty hours in cycle at defined intervals. The mass changes per unit area are measured using digital balance during the intervals of cycle. Surface oxide formations are studied with SEM and XRD analysis.

\section{RESULT AND DISCUSSION}

\section{A. Mass Change:}

The samples exposed to hot air and mixed salt environment at elevated temperatures $\left(900^{\circ}\right.$ and $\left.1000^{\circ} \mathrm{C}\right)$ are observed regularly. The mass change per unit area $\left(\mathrm{mg} / \mathrm{cm}^{2}\right)$ are empirically calculated and plotted in Figure $1 \mathrm{a}$ and $1 \mathrm{~b}$. The performance of Inconel718 without salt environment is better than Hastelloy with a maximum mass change of $0.238 \mathrm{mg} / \mathrm{cm}^{2}$ and $1.418 \mathrm{mg} / \mathrm{cm}^{2}$ after fifty hours during exposure at high temperature of $900^{\circ} \mathrm{C}$ and $1000^{\circ} \mathrm{C}$ respectively. However, the Hastelloy has maximum of 0.78 $\mathrm{mg} / \mathrm{cm}^{2}$ and $2.18 \mathrm{mg} / \mathrm{cm}^{2}$ for the same condition without salt mixture exposed to air at $900^{\circ} \mathrm{C}$ and $1000^{\circ} \mathrm{C}$. Presence of iron in the Hastelloy has high affinity towards oxygen at high temperature and produced iron oxide over the surface with high mass reaction. The oxide scale formation is rapid and tends to increase the mass change catastrophically. 
Adversary, the presence of aluminium element in the superalloy has produced protective oxides during exposure and not table for a prolonged exposure. The iron oxides are the stable oxides and aluminium oxides are not stable when molten salt mixture is applied. This was evidently proved with the samples exposed to high temperature with salt mixture. During the experimentation, the mass change observed with molten salt environment is high in Inconel617 compared to Hastelloy. Thus, the corrosion rates of the materials are controlled by the formation of metal oxide scale. The surface characterization of the materials is studied by XRD, SEM and EDS and it's explained in the following sections.

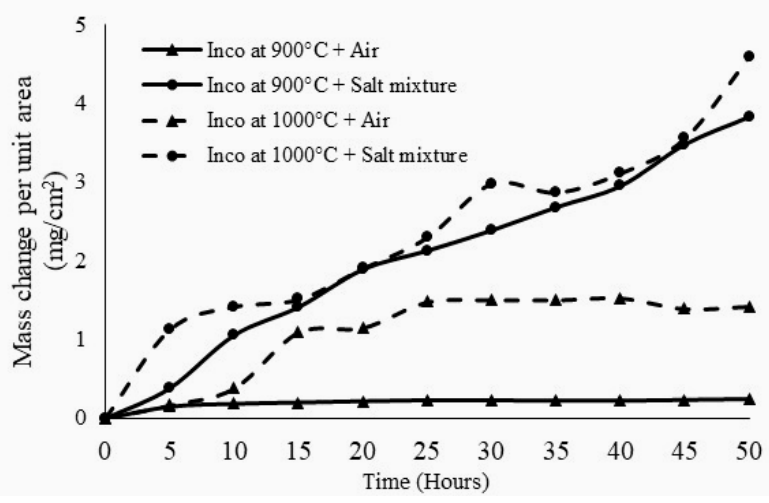

Fig.1a.Performance of Inconel617 alloy with and without salt mixture at elevated temperatures.

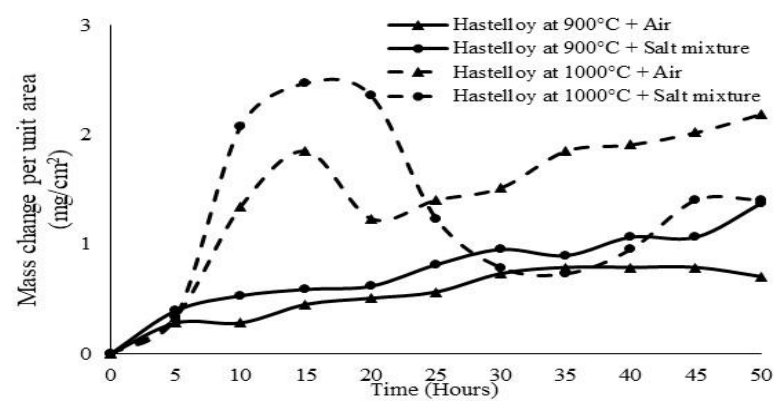

Fig.1b. Performance of Hastelloy with and without salt mixture at elevated temperatures.

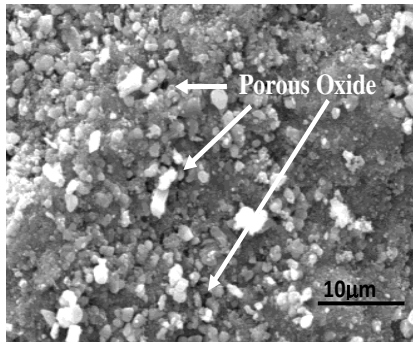

Inconel617micrograph

Fig 2. Surface morphology the samples exposed to air at $900^{\circ} \mathrm{C}$

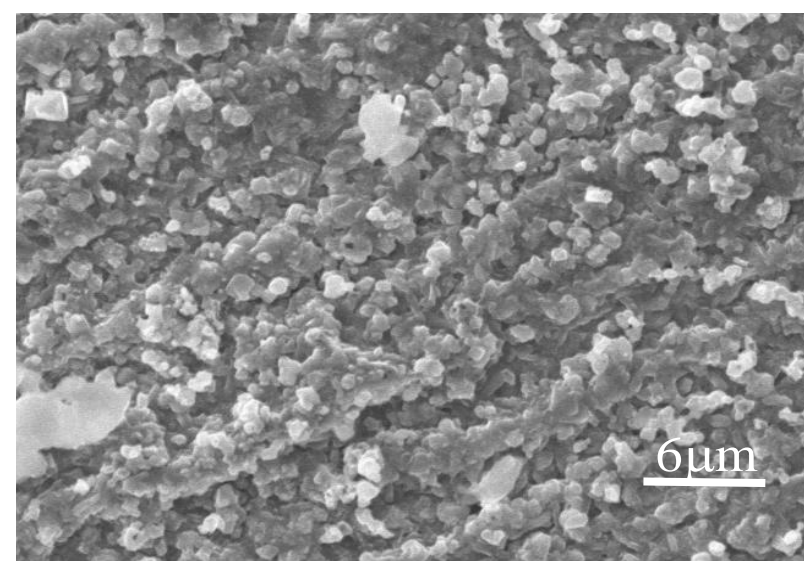

Fig.3.SEM micrograph of Hastelloy exposed to air at $1000^{\circ} \mathrm{C}$.

Exposed samples are investigated with scanning electron imaging techniques to study the surface morphology of the samples. The oxide scale formation at $900^{\circ} \mathrm{C}$ shows less oxide scale in Hastelloy and aggressive in Inconel617. However, the oxide formation in Hastelloy is in the form of iron oxide, since the flakes are nucleated in similar structure. However, in Inconel617 alloy, the oxide structure are agglomerated. It is combination of multi oxides. To justify the surface oxide formation, samples are further investigated with $\mathrm{X}$ - ray diffraction analysis. With reference to intensity and angle, the oxides are predicted. Thus analysed oxides from Inconel617 alloy is as $\mathrm{NiO}, \mathrm{Cr}_{2} \mathrm{O}_{3}, \mathrm{Fe}_{2} \mathrm{O}_{3}, \mathrm{Al}_{2} \mathrm{O}_{3}, \mathrm{NiCr}_{2} \mathrm{O}_{4}$ and $\mathrm{NiMoO}_{4}$. From Pilling BedworthRatio (PBR) it shows that compressive stress has developed its leads to penetrate the crack in the oxide and material has spall off. Due to presence of $\mathrm{Al}_{2} \mathrm{O}_{3}$ and $\mathrm{Cr}_{2} \mathrm{O}_{3}$ in the substrate which acts as a sacrificing element and which leads to protect the material from the oxidation.

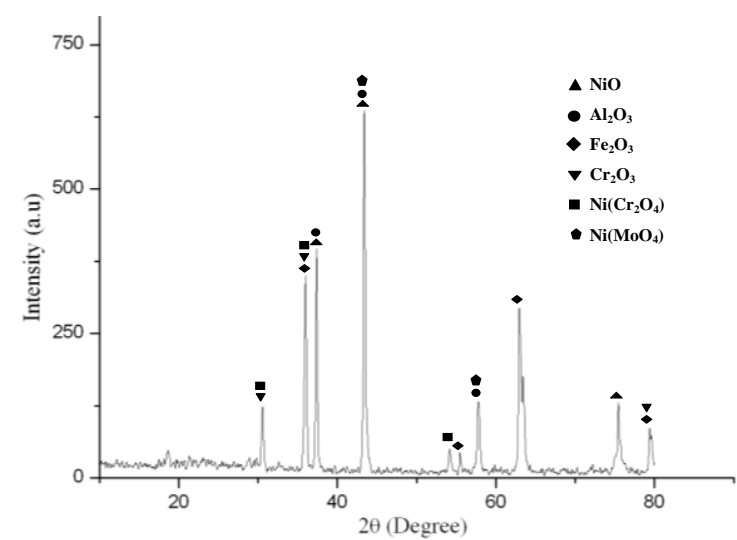

Fig4. XRD analysis of Inconel617 exposed to a mixed salt environment at $900^{\circ} \mathrm{C}$

\section{CONCLUSION}

High temperature behavior nickel - based superalloys are investigated with and without molten salt environment. Following are the major findings from the analysis:

The samples are prone to surface degradation in all conditions. At the same, the behavior of Inconel617 is better than Hastelloy at $900^{\circ} \mathrm{C}$ and Hastelloy is better than Inconel617 at $1000^{\circ} \mathrm{C}$. The density of the oxide has induced the changes. 
Surface morphology is rapid and aggressive in Inconel617. At the same, the surface damage found less in Hastelloy. This is because of iron oxide in the surface.

The oxide formation on the surface are analyzed through XRD and confirmed the results

\section{REFERENCES}

1. Maledi N B, Potgieter J H, Sephton M, Cornish L A, Chown Land Suss J. S. Hot corrosion behaviour of Pt-alloys for application in the next generation of gas turbines International platinum conference Afr. Inst.Min. Metall,2006, pp. 81- 90

2. J S, Hu Z Q, Murata Y, Morinaga M and Yukawa Design and development of hot corrosion-resistant Nickel- Base Single crystal superalloys by the d- electrons alloy design theory, Metallurgical and Materials Transactions, Nov 1999, vol 24.

3. Chen $\mathrm{H}$, Chen W, Mukherji D, Wahi R P and Wever $\mathrm{H}$ Z.Metalkd,1995, pp.86-423

4. Li J and Wahi R P ActaMetall. Mater,1995, pp 43 -50.

5. Wang Y, Mukherji D, Chen W, Kuttner T, Wahi R P and Wever H ZMetalkd,1995,pp $86-365$

6. Konter, M., and M. Thumann. "Materials and manufacturing of advanced industrial gas turbine components." Journal of Materials Processing Technology, 2001, pp 386-390

7. Eliaz, N., G. Shemesh, and R. M. Latanision. "Hot corrosion in gas turbine components." Engineering failure analysis 9, no. 1 (2002) 31-43.

8. Gallardo, J. M., J. A. Rodríguez, and E. J. Herrera. "Failure of gas turbine blades, 2002,pp 264-268.

9. Khajavi, M. R., and M. H. Shariat. "Failure of first stage gas turbine blades." Engineering Failure Analysis, 2004, pp 589-597.

10. Stringer,J."High-temperature corrosion of superalloys." Materials Science and Technology, 1987, pp 482-493.

11. Pettit, F. S., G. H. Meier, M. Gell, C. S. Kartovich, R. H. Bricknel, W. B. Kent, and J. F. Radovich. "Oxidation and hot corrosion of superalloys." Superalloys, 1984, pp. 651-687.

12. J.Stringer:'High-temperature corrosion of superalloys', Mater. Sci. Technol, 1987, pp. 482-493.

13. Ren, X., K. Sridharan, and T. R. Allen. "Corrosion behavior of alloys 625 and 718 in supercritical water." Corrosion 2007, pp. 603-612. 